\title{
Optical Anisotropy of Polyimide and Polymethacrylate Containing Photocrosslinkable Chalcone Group in the Side Chain under Irradiation of a Linearly Polarized UV Light
}

\author{
Dong Hoon Choi ${ }^{\star}$ and Young Kwan Cha \\ College of Emiroment \& Applied Chemistry, Materials Center for Information Displav. Institute of Natural Sciences, \\ Kiving Hee Universitv. I Seocheon, Yongin. Kivmgki 149-701. Korea \\ Received November 14, 2001
}

\begin{abstract}
Photocrosslinkable soluble polyimide and polymethacrylate compound were synthesized for studying the optically induced anisotropy of the thin films. Chalcone group was introduced into the side chain unit of two polymers. We observed a photodimerization behavior between the double bonds in the chalcone group and an optical anisotropy of these materials by irradiation of a linearly polarized UV light (LPL). Optical anisotropy of the thin film was also investigated by using polarized UV absorption spectroscopy. The dynamic property of optical anisotropy in photoreactive poly imide was compared to that in polymethacrylate containing chalcone group in the side chain.
\end{abstract}

Keywords : Optical anisotropy. Clalcone. Photodimerization, Poly imide. Polymethacrylate.

\section{Introduction}

Polymeric materials have recently attained remarkable interests as photoreactive materials. Photochenical reactions in organic polymeric materials can induce much change in physical properties such as solubility, optical transparency. dielectric constant. and refractive index. A number of studies were performed to fabricate the alignment layer of liquid crystals (LCs) using photoreactive polymers. ${ }^{1.5}$

The photoalignment technique for $\mathrm{LC}$ display has received much attention in recent years because of its clean and photo-patternable system. ${ }^{6.13}$ Many kinds of photoreactive polymers that can undergo anisotropic isomerization or photocrosslinking reactions have been reported for the photoalignment of LC ${ }^{8-16}$ Nenatic liquid crystal (NLC) can be aligned homogeneously on the photoreactive polymer film which is usually exposed to a linearly polarized light (LPL).

From the practical point of view. the thermal and photostability of the alignment layer is very important and the aligiment layer must be transparent in a visible region for the display device. A photo-crosslinkable polymer system can offer high thermal stability because of its three dimensional network and several photo-crosslinkable polymers for the LC photo-aligmment have been investigated. ${ }^{13-16}$ Polymers containing unsaturated aromatic acid or ester units. especially the cinnamic ester and cinnamic acid derivatives were studied for phototransformation phenomena. which occurred during the irradiation with UV light $(\lambda=250-300 \mathrm{~mm})$. For example anisotropic [2+2] cycloaddition of poly viny lcinnamate (PVCi) film can induce irreversible low molecular weight-liquid crystal (LMW-LC) alignment. The polymers containing chalcone group in the side chain were also frequently studied for application to LC photo-aligument

Contesponding Author. e-mail: dhchoigkhu.ac.kr layer. The induction mechanism of optical anisotropy is identical with that in polyvinylcimnamate. ${ }^{17.19}$ Above polymeric materials could show the possibility to apply them to LC aligument layer only due to angular selective $[2+2]$ photodimerization process. However, most of the photocrosslinkable polymer showed that the optical anisotropy of the thin film increased at the initial stage of UV irradiation and gradually diminished under a continuous irradiation. If the optical anisotropy continue to increase or stabilize under a continuous UV irradiation, LC alignment can be observed to quite stable.

Among many promising photosensitive groups, a clalcone group has been well studied and can be used in photocrosslinkable polymers because it affords high sensitivity to UV radiation $(\lambda=300-350 \mathrm{~nm})$. Because of poor solubility arising from the rigid-rod nature of chalcone backbone polymers. most research works involved only polymers that contain the chalcone unit in the side chain. ${ }^{20.22}$

In this work, we also synthesized a new photoreactive soluble polyinide and polymethacrylate. Chalcone group was introduced into the side chain unit of the new photoreactive polymers. which is highly sensitive to the LPL photochemically: The capability of photocrosslinking of new compounds was demonstrated using UV-Vis absorption spectroscopic analysis. The optical anisotropy of the film induced by irradiation of a linearly polarized UV light is also investigated by using the polarized UV absorption spectroscopy. Photocrosslinking was performed to elaborate the very dense and rigid matrix after UV exposure and angular selective photochenical reaction was performed to induce high optical anisotropy.

\section{Experimental Section}

Scheme 1 and 2 show the synthetic schemes of the 
photosensitive material such as soluble polyinide and polymethacrylate used in this study.

\section{Synthesis of +-hydroxychalcone}

(3-(4-Hydroxy-phenyl)-1-phenyl-propenone): To a solution of $10 \mathrm{~g}(0.082 \mathrm{~mol})$ of t-hydroxybenzaldehyde in $300 \mathrm{ml}$ ethanol. $29.52 \mathrm{~g}(0.246 \mathrm{~mol})$ acetophenone was added and the reaction mixture was cooled, followed by the addition of $6.56 \mathrm{~g}(0.164 \mathrm{~mol})$ of sodium hydroxide dissolved in $11.66 \mathrm{~mL}$ of water. The reaction mixture was stirred for two days at room-temperature. After evaporation of ethanol under reduced pressure. the product was dissolved in ethylacetate and washed with water. The solution was dried under $\mathrm{Na}_{2} \mathrm{SO}_{4}$ and concentrated. Then precipitation was done in cold hexane to give $70 \%$ yield. m.p. $178^{\circ} \mathrm{C}$.

${ }^{1} \mathrm{H}-\mathrm{NMR}$ (DMSO-d $\left.\mathrm{d}^{6}\right) \delta(\mathrm{ppm}) 7.5(1 \mathrm{H}$ in ethylenic $-\mathrm{C}$ $=\mathrm{CH}-\mathrm{C}(=\mathrm{O})-\mathrm{d}) .7 .85(\mathrm{lH}$ in ethylenic $-\mathrm{CH}=\mathrm{C} \underline{\mathrm{H}}-\mathrm{C}(=\mathrm{O})-\mathrm{d})$. $6.9-8.1$ (9H in aromatic, $\mathrm{m})$

Synthesis of +-(2-hydroxyethoxy)chalcone: To a solution of $5 \mathrm{~g}(0.0223 \mathrm{~mol})$ of 4-hydroxychalcone in $50 \mathrm{~mL}$ of ethanol, $1.784 \mathrm{~g}(0.045 \mathrm{~mol}) \mathrm{NaOH}$ dissolved in $3.17 \mathrm{~mL}$ of $\mathrm{H}_{3} \mathrm{O}$ was added and the reaction mixture was cooled. followed by the addition of $5.4 \mathrm{~g}(0.067 \mathrm{~mol})$ of 2-chloroethanol. The reaction mixture was stirred for $24 \mathrm{hr}$ at $50^{\circ} \mathrm{C}$. After evaporation of ethanol under reduced pressure. the product was dissolved in $\mathrm{CH}_{2} \mathrm{Cl}_{3}$. washed with $1 \mathrm{~N} \mathrm{NaOH}$ aqueous solution and then purified by crystallization from $\mathrm{CH}_{2} \mathrm{Cl}_{2} /$ petroleum ether $(60 \mathrm{~mL} / 80 \mathrm{~mL})$ to give $62 \%$ yield. m.p. $52^{\circ} \mathrm{C}$.

${ }^{1} \mathrm{H}-\mathrm{NMR}$ (DMSO-d $\left.\mathrm{d}^{6}\right) \delta(\mathrm{ppm}) 4.05 .4 .15(2 \mathrm{H}, 2 \mathrm{H}$ in $\mathrm{O}-$ $\left.\mathrm{C} \underline{H}_{-}-\mathrm{CH}_{2}-\mathrm{O}-\mathrm{t}\right), 7.45(\mathrm{lH}$ in ethylenic $-\mathrm{C} \underline{\mathrm{H}}=\mathrm{CH}-\mathrm{C}(=\mathrm{O})-\mathrm{d})$. $7.8(\mathrm{lH}$ in ethylenic $-\mathrm{CH}=\mathrm{C}-\mathrm{H}-\mathrm{C}(=\mathrm{O})$ - d). 6.9-8.1 (9H in aromatic, $\mathrm{m}$ ).

Synthesis of photoreactive polymethacrylate (PMAC): To a solution of $4 \mathrm{~g}(0.0178 \mathrm{~mol})$ of 4-hydroxychalcone in $100 \mathrm{~mL}$ benzene, $2.17 \mathrm{~g}(0.0267 \mathrm{~mol})$ trietlylanine was added. $2.8 \mathrm{~g}(0.0267 \mathrm{~mol})$ of methacryloyl chloride was added dropwise into the solution at room temperature. The reaction mixture was stirred for $2+\mathrm{hr}$. After washing the misture with water three times. it was then concentrated to a half volume of the initial one. It was poured into hexane to obtain the precipitate. We could collect the white solid methacrylate product (yield. $82 \%$ ).

l g $(0.0034 \mathrm{~mol})$ of the methacrylate monomer was dissolved in $15 \mathrm{~mL}$ of NMP and $0.0148 \mathrm{~g}(0.09 \mathrm{mmol})$ of AIBN were also added to a solution. The reaction mixture was stirred for two days at $65-70^{\circ} \mathrm{C}$ under argon atmosphere. After precipitation into methanol. the solid product was purified by precipitation from methanol/THF to give $90 \%$ yield. $\mathrm{T}_{\mathrm{g}} 103^{\circ} \mathrm{C}$

${ }^{1} \mathrm{H}-\mathrm{NMR}$ (DMSO-d $) \delta(\mathrm{ppm}) 1.4-1.6\left(3 \mathrm{H}\right.$ in $\mathrm{CH}_{3}-(\mathrm{CO}-)$ $\left.\mathrm{C}\left(\mathrm{CH}_{2}-\right)-\right), 1.6-1.7\left(2 \mathrm{H}\right.$ in $\left.\mathrm{CH}_{3}-(\mathrm{CO}-) \mathrm{C}\left(\mathrm{CH}_{-}-\right)-\right) .7 .5-7.6(\mathrm{lH}$ in ethylenic $-\mathrm{CH}=\mathrm{CH}-\mathrm{C}(=\mathrm{O})-)^{2} \cdot 7.7-7.8(1 \mathrm{H}$ in ethylenic $-\mathrm{CH}=\mathrm{C} \underline{\mathrm{H}}-\mathrm{C}(=\mathrm{O})-$ ). $7 \cdot 4-8.0$ (9H in aromatic group)

Synthesis of chalcone-based soluble polyimide (CSPI): $1 \mathrm{~g}(2.25 \mathrm{mmol})$ of $4 . t^{\prime}$-(hexafluoroisopropy lidene)diphthalic antydride was added to a solution of $0.824 \mathrm{~g}(2.25$ inmol) of 2.2-bis(3-amino-4-hydroxyphenyl)hexafluoropro- pane) in $20 \mathrm{~mL}$, NMP.

After the reaction mixture was stirred for 12 lurs at room temperature, $0.53 \mathrm{~g}(6.75 \mathrm{mmol})$ of pyridine and $0.92 \mathrm{~g}$ ( 9 mimol) of acetic anthydride were added dropwise followed by stirring for $\mathrm{lhr}$ at room temperature. It kept stirring for thrs at $50^{\circ} \mathrm{C}$. After filteration. the product (soluble polyimide, SPD was obtained by precipitation into methanol to give $70 \%$ yield

To a solution of $1 \mathrm{~g}(1.3 \mathrm{mmol})$ of SPI in $10 \mathrm{~mL}$ THF. 1.04 $\mathrm{g}$ of $(3.87 \mathrm{mmol}) 4$-(2-hydroxyethoxy)chalcone and $1.705 \mathrm{~g}$ (6.5 mmol) of triphenylphosphine $\left(\mathrm{PPh}_{3}\right)$ were added and the reaction mixture was cooled to $0^{\circ} \mathrm{C}$, followed by the addition of $1.314 \mathrm{~g}(6.5 \mathrm{mmol})$ of disopropyl azodicarbosylate (DIAD). The reaction mixture was stirred for $12 \mathrm{hr}$ at 80 ${ }^{\circ} \mathrm{C}$. After filtration, the product (CSPI) was obtained by precipitation into methanol to give $65 \%$ yield. $\mathrm{T}_{\mathrm{g}} 158^{\circ} \mathrm{C}$

${ }^{3} \mathrm{H}-\mathrm{NMR}$ (DMSO-d $\left.{ }^{6}\right) \delta(\mathrm{ppm}) 4.2-4.5\left(8 \mathrm{H}\right.$ in $-\mathrm{O}-\mathrm{C}_{2}=$ $\left.\mathrm{C} \mathrm{H}_{-}=\mathrm{O}-\right), 7.4-7.5$ (2H in ethylenic $\left.-\mathrm{CH}=\mathrm{CH}-\mathrm{C}(=\mathrm{O})-\right), 7.8-7.9$ $(2 \mathrm{H}$ in etlyylenic $-\mathrm{CH}=\mathrm{C} \underline{\mathrm{H}}-\mathrm{C}(=\mathrm{O})-), 7.2-8.2(30 \mathrm{H}$ in aromatic group)

\section{Characterization}

UV-Vis absorption spectroscopy: Absorption spectra were obtained using a Hewlett Packard UV-Vis 8453 spectrophotometer (PDA type, $\lambda=190-1100 \mathrm{~lm}$ ). The polymers were dissolved in THF and cast onto quartz plate followed by drying in vacuo at $50^{\circ} \mathrm{C}$ for $2 \mathrm{lur}$. All the polymer films on quartz plates were irradiated with a linearly polarized $\mathrm{He}-\mathrm{Cd}$ laser (Liconix $3675 \mathrm{NX} . \lambda=325 \mathrm{~mm}$. $I_{\max }=210 \mathrm{~mW} / \mathrm{cm}^{2}$ ). The intensity was measured by using a 13PEM001 (MELLES GRIOT) detector and power meter.

For the polarized absorption spectroscopic study to investigate the dichroism and the order parameter during UV illumination. we equipped Glan-Taylor polarizer in front of the probe beam in the spectrophotometer.

FT-IR spectroscopy: Film specimens of the synthesized polymers on $\mathrm{KBr}$ window were prepared from tetralydrofuran solution ( $2 \%$ ). After the solvent was evaporated, the films were stored under vacuum at $50^{\circ} \mathrm{C}$ for at least 3 hours to remove the residual solvent completely. The sample on the $\mathrm{KBr}$ window was subjected to random polarized UV light irradiation and the FT-IR spectra were taken with Bruker IFS66: before and after UV exposure.

NMR spectroscopy: Proton NMR spectrum was recorded with Varian 200 NMR spectrometer. DMSO-d 6 was used as a solvent for recording NMR spectra. Degree of substitution of chalcone group in polyimide (CSPI) was determined by using peak integration method.

\section{Results and Discussion}

Synthesis and characterization: Synthetic procedures were simply illustrated in Scheme $I$ and 2 . Photoreactive polyinide and polymethacrylate contain unsaturated carbonyl moieties as photosensitve groups in the side chain. 4Hydroxychalcone and 4-(2-hydroxyethoxy)chalcone were synthesized following the conventional method. which gave a good yield. In polymethacrylate (PMAC). we firstly 


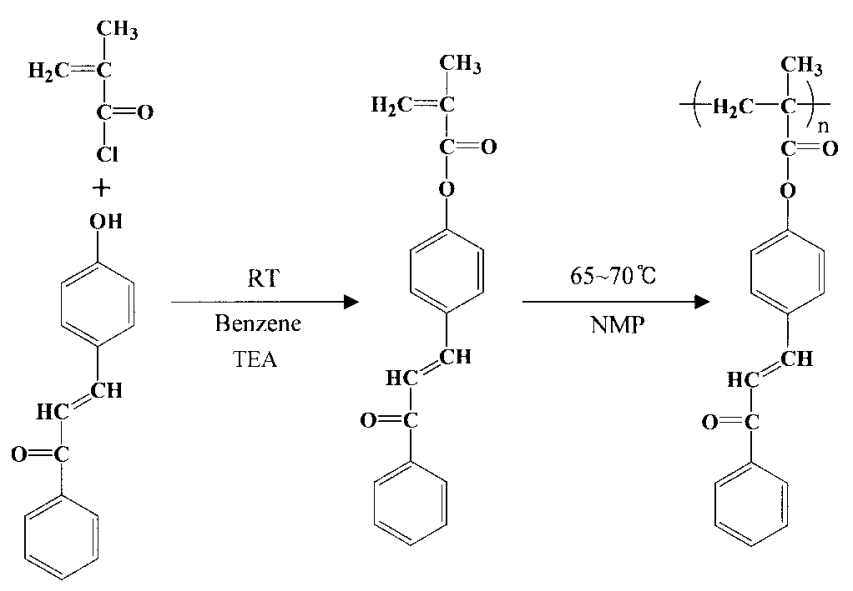

Scheme 1. Synthetic procedure for polymethacrylate (PMAC) bearing a chalcone group in the side chain.

synthesized the methacrylate monomer using methacryloyl chloride and 4-hydroxychalcone. The methacrylate monomers were polymerized under a radical initiator. The soluble polyinde was synthesized by condensation of specific dianhydride and diamine bearing two trifluoromethyl groups. respectively. In this case, the diamine has two hydroxy groups in the benzene ring. In order to avoid the geometrical hindrance and lowering the reaction yield, we anchored the chalcone with ethylene spacer such as 4 -(2-hydroxyethoxy)chalcone. The substitution was successfully performed and the degree of substitution was found to be $80 \%$ determined by NMR spectroscopic technique. The structures of two polymers were well confirmed by NMR spectral analysis. (See Figure 1). The intrinsic viscosities of PMAC and CSPI were determined to be 0.07 and 0.20 in tetrahydrofuran at 25 ${ }^{\circ} \mathrm{C}$, respectively. Those polymers are well soluble even in acetone, chloroform. methylene chloride, tetrahydrofuran etc. The glass transition temperatures, $T_{p}$ of PMAC and

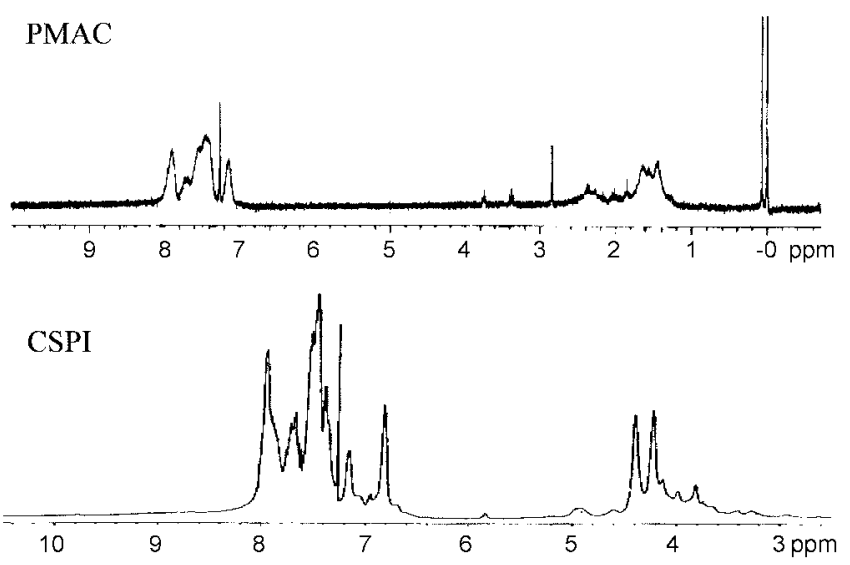

Figure 1. NMR spectra of the synthesized polymethacrylate (PMAC) and polyimide (CSPI).

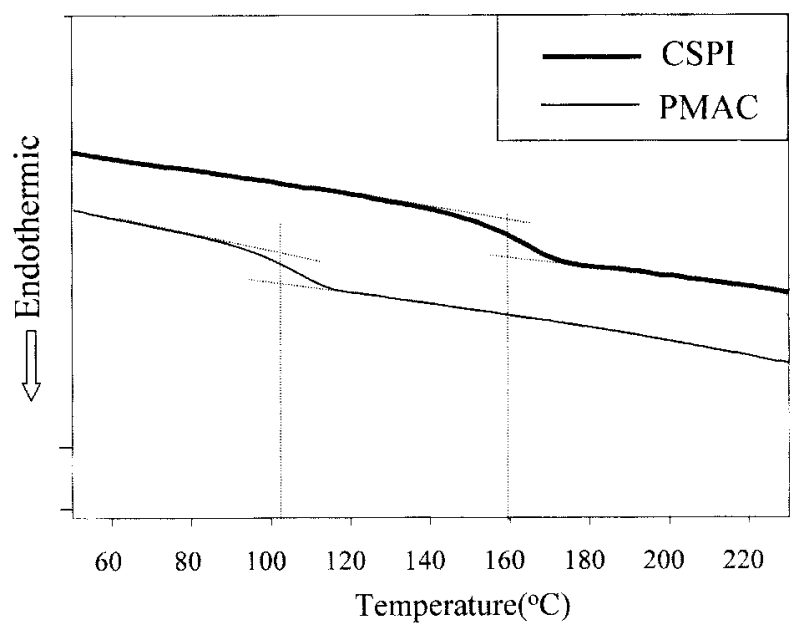

Figure 2. DSC thermograms of the PMAC and CSPI.

CSPI is 103 and $158^{\circ} \mathrm{C}$, respectively. (See Figure 2)

UV-Vis absorption spectroscopic study in photocross-

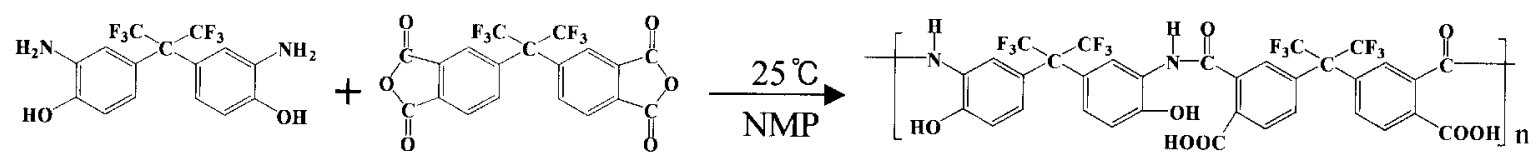<smiles>CC(C)(C)c1ccc2c(c1)C(=O)N(c1cc(C(C)(C)C)ccc1OCOc1ccc(C(C)(C)C)cc1C(C)(C)C)C2=O</smiles>

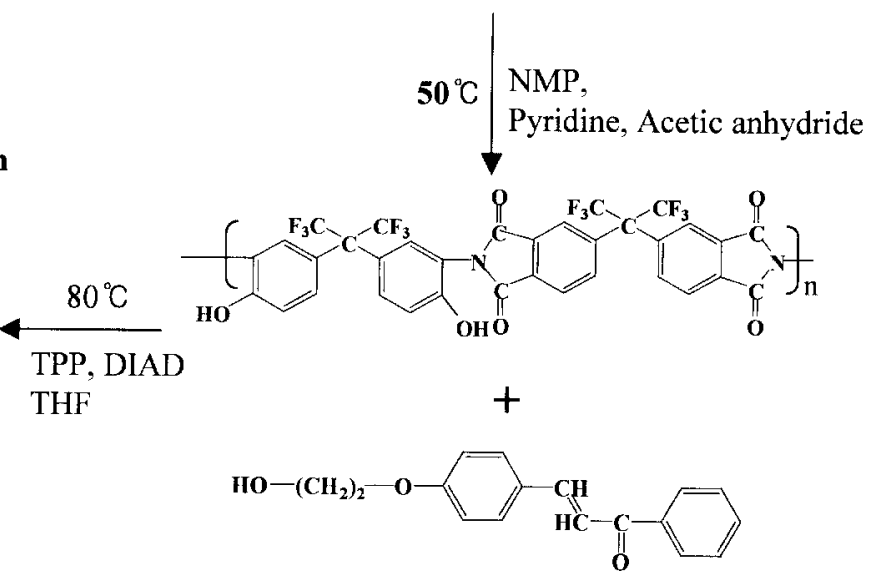

Scheme 2. Synthetic procedure for polyinide (CSPI) bearing a chalcone group in the side chain. 

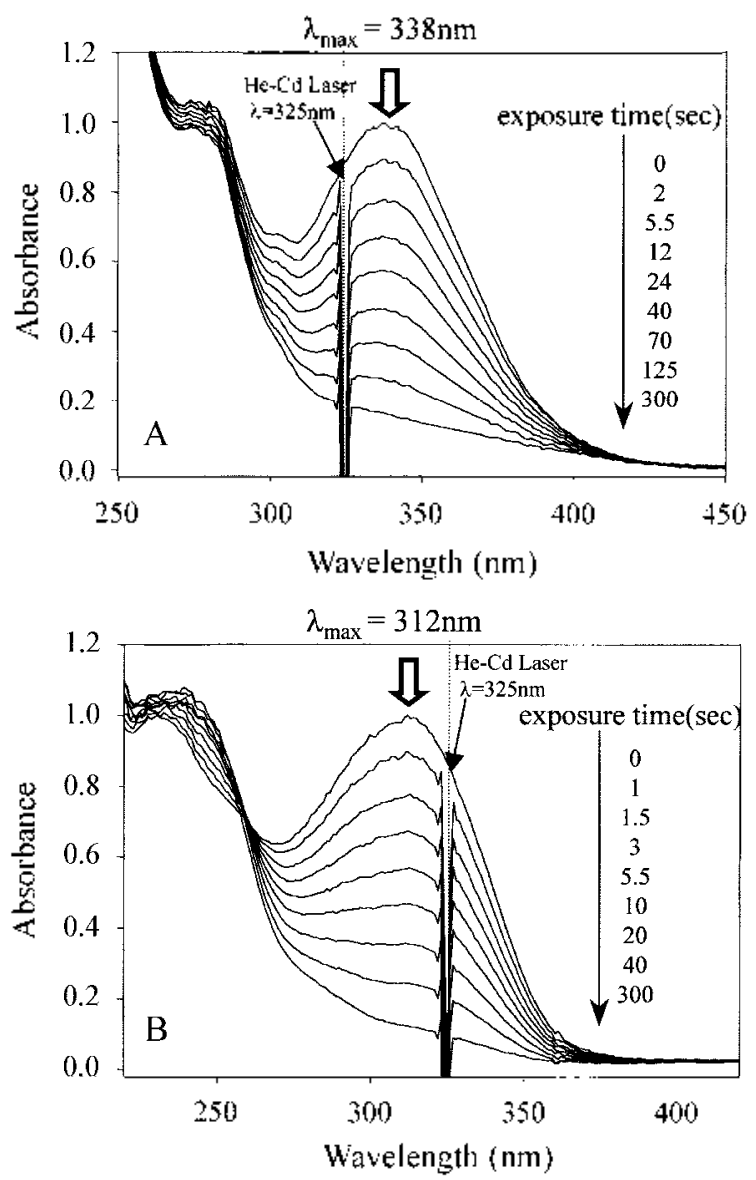

Figure 3. Absorption spectral changes of the polymer films irradiated with randon polarized UV light at room temperature. A: CSPI, B: PMAC

linking reaction: The photoirradiation of the polymer films was carried out by using a He-Cd laser $\left(\mathrm{I}=210 \mathrm{~mW} / \mathrm{cm}^{3}\right)$. The UV-Vis absorption spectra of the thin film of polyimide (A) and polymethacrylate (B) are given in Figure 3. The spectra were recorded during UV irradiation simultaneously.

The UV absorption changes at $\lambda_{\max }$ in the two compounds caused by photoreaction were investigated using thin films on quartz plate. Chalcone units underwent a crosslinking reaction by $[2+2]$ cycloaddition between a UV excited chalcone group and an unexcited chalcone group (ground state) on another ${ }^{2021}$ The disappearance of the double bond in chalcone unit was observed clearly in this spectroscopic experiment. The maximum absorbance due to the $\pi$-electronic conjugation decreased rapidly. In Figure 4, the change of the maximum absorbance was illustrated with the exposure time. The change of the absorbance was fitted to the stretched exponential decay function to determine the rate constant. $\mathrm{k}$ in photodimerization. The time constants, $\tau$ $(=1 / \mathrm{k})$ of polyinide and polvmethacrylate were deternined 42.86 and $11.8 \mathrm{sec}$. respectively.

$$
\mathrm{A}(\mathrm{t}) / \mathrm{A}(0)=\exp \left[-(\mathrm{kt})^{\beta}\right]+\mathrm{R}=\exp \left[-(\mathrm{t} / \tau)^{\beta}\right]+\mathrm{R}
$$

Polyimide shows a relatively small reaction rate compared to that of polymethacrylate, which is attributable to the

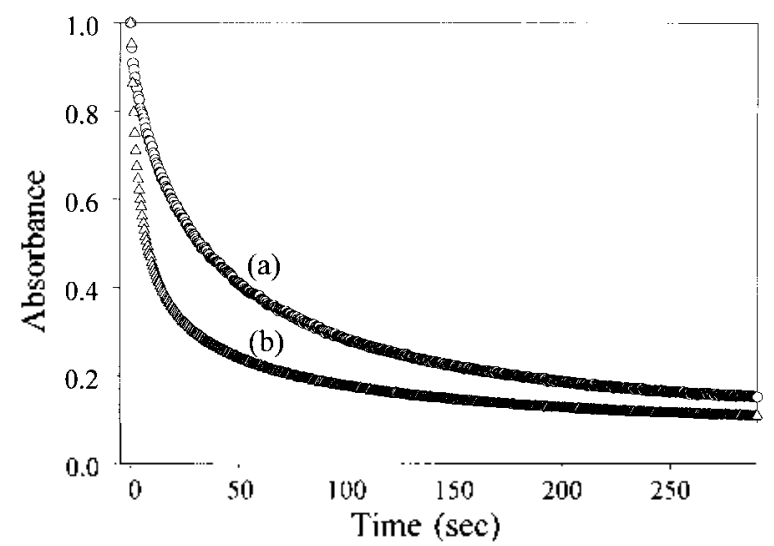

Figure 4. Variation of the absorbance at $\lambda_{\text {max }}$ with the UV exposure time. (a) CSPI, (b) PMAC.

rigidity of the main chain backbone. Additionally, chalcone groups are geometrically restricted to retard the photodimerization. It can be conjectured that the stabilized cyclobutane structure could not be formed by intramolecular reaction but by intermolecular reaction. The density of the chalcone group in PMAC is higher so that internolecular crosslinking reaction can be more favorable. Resulting from above reasons. the residual absorbance (R) of CSPI is larger than that of PMAC.

The infrared spectroscopy of polyimide and polymethacrylate before and after UV exposure: In order to monitor the photoreaction of the olefinic. $-\mathrm{C}=\mathrm{C}$ - double bonds of the chalcone group, we utilized the FT-IR spectroscopy. Figure 5 shows the localized FT-IR spectra of the polyimide (A) and polymethacrylate (B). The spectra. plotted on an absolute absorbance scale in the range from 1900 to $800 \mathrm{~cm}^{-1}$. were recorded from the same sample before and after UV exposure (light source: high pressure $\mathrm{H}_{\mathrm{g}}$ lamp with $365 \mathrm{~nm}$ bandpass filter. $\left.t=30 \mathrm{~min} . \mathrm{I}=23 \mathrm{~mW} / \mathrm{cm}^{2}\right)$. There are significant changes in the infrared spectra of two compounds indeed occurred upon the UV-irradiation. The $-\mathrm{C}=\mathrm{C}$ stretching vibration mode at $1601-1602 \mathrm{~cm}^{-1}$ is observed to decrease siguificantly by UV exposure. Compared to the absorbance change at $1601 \mathrm{~cm}^{-1}$ in PMAC, the extent of decrease of the absorbance at $1602 \mathrm{~cm}^{-1}$ is relatively small. We can expect two factors for this phenomenon. First, it can be due to the difference of the rigidity of the backbone and the density of chalcone group. Additionally, this is attributed to the fact that the density of the double bond in the benzene ring of polyinide is much higher than that of PMAC. The absorption spectral band from ethylenic double bond is nomally superposed with the absorption bands of the double bond in the benzene ring. In addition. the intensity of the $\mathrm{C}=\mathrm{O}$ unsaturated ketone carbonyl stretcling band at $1663.1667 \mathrm{~cm}^{-1}$ decreases systematically with UV exposure time and a new absorption band, attributed to a saturated ketone carbonyl stretching vibration, at $1681.1682 \mathrm{~cm}^{-1}$ appears in the spectra of the two polymers after UV irradiation.

Polarized UV-Vis absorption spectroscopy under irradiation of a linearly polarized light: The films of the two 

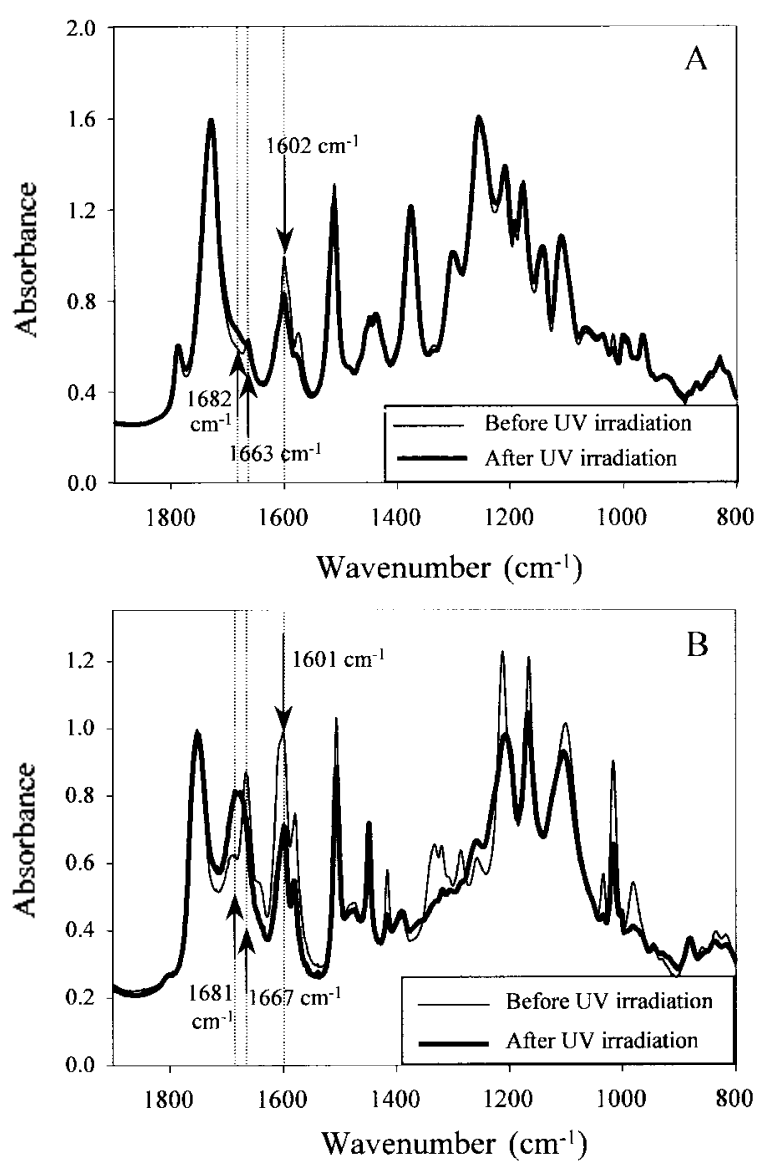

Figure 5. Intrared spectra of the two polymer films betore and after UV iradiation. A: CSPI, B: PMAC.

polymers showed anisotropic spectra after exposure to LPL. We recorded the absorption spectrun every 0.5 second during irradiation of a linearly polarized $\mathrm{He}-\mathrm{Cd}$ laser $\left(\mathrm{I}=210 \mathrm{~mW} / \mathrm{cm}^{2}\right)$. In Figure 6 , the representative polarized absorption spectra were illustrated using the two polyners. We can observe the change in UV absorption spectrum and dichroism. $A_{\|}$denotes the parallel absorption and $A_{\perp}$ perpen-
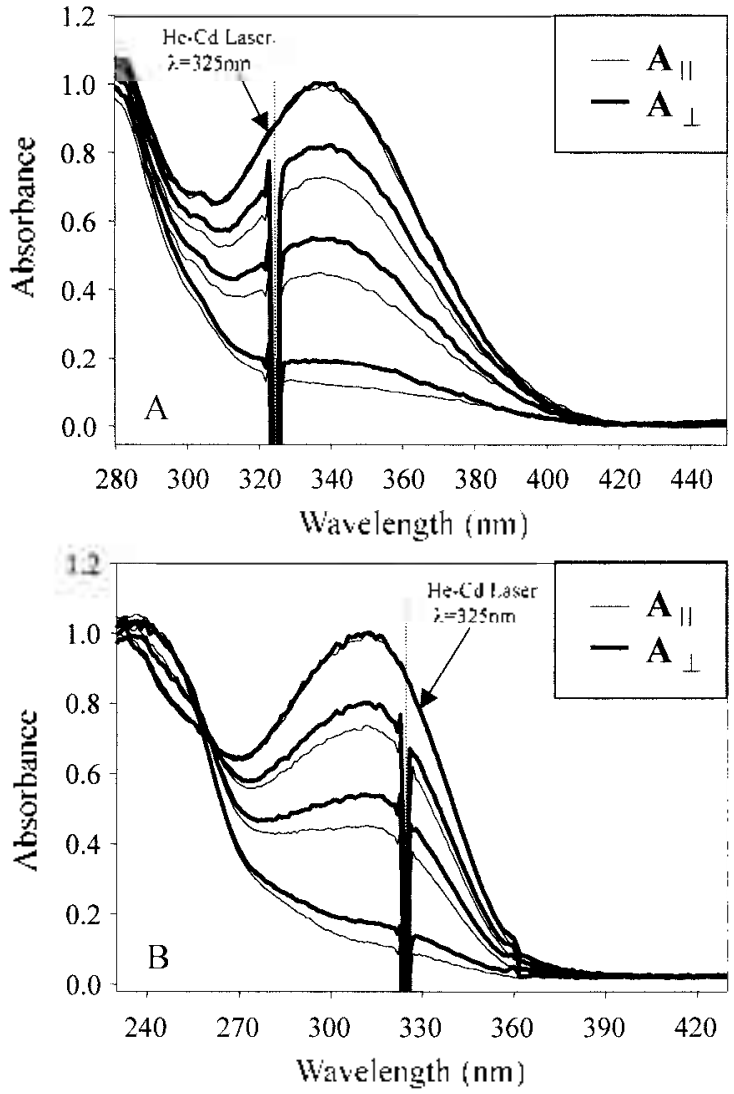

Figure 6. Polarized absorption spectra of the chalcone-epory film exposed to a linearly polarized UV light with the change of the irradiation time. A: CSPI, B: PMAC.

dicular to electric field of the incident LP-UV pump light. Exposure time dependence of the parallel and perpendicular absorbance at $\lambda_{\text {max }}$ was investigated during irradiation of the linearly polarized UV light from $\mathrm{He}-\mathrm{Cd}$ laser. The decrease in the absorption at $\lambda_{\text {max }}$ was evident, which is attributed to the formation of cyclobutane rings through $|2+2|$ cycloaddition of the carbon-carbon double bonds in chalcone moieties.

The parallel absorbance at $\lambda_{\max }$ was observed to be snaller
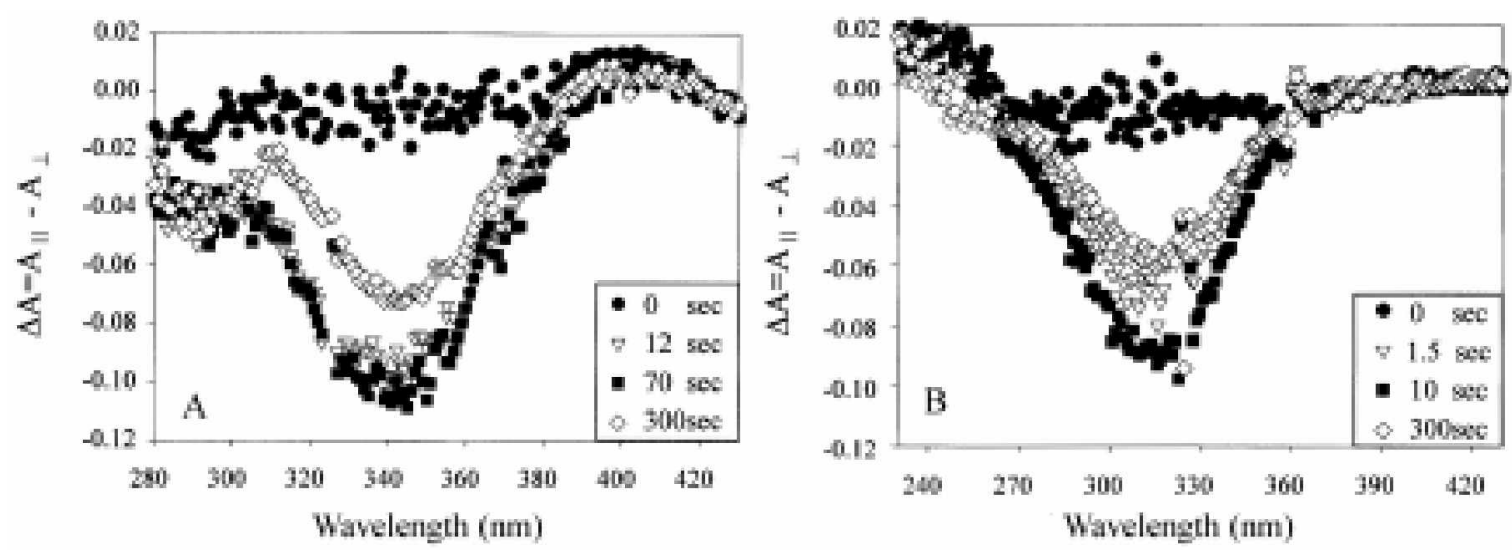

Figure 7. UV absorption difterence spectra $\left(\triangle A=A_{\mid}-A_{\perp}\right)$ of the two polymer films irradiated with LP-UV light at room temperature. $A_{\mid}$is the direction of parallel absorption which coincides with the electric vector of LP-UV direction and $A_{\perp}$ is the direction of perpendicular absontion, respectively. A: CSPI, B: PMAC. 
than the perpendicular absorbance in the whole range of the irradiation time period. Using the two traces of the absorbance, we could analyze the optical anisotropy of the thin film in terms of the difference of the absorbance and the dichroisnt

In Figure 7, the difference spectra of the absorbance between the perpendicular and parallel to the polarization direction of pump bean were shown. The dufference of the absorbance $\left(\triangle A=A_{1}-A_{\perp}\right)$ of poly unide and polymethacry late at $\lambda_{\text {max }}$ reached to the mininum after 70 and $10 \mathrm{sec}$ exposure. respectively. Then the difference value increased gradually under further UV irradiation. Therefore. for longer period of UV exposure. the anisotropy of the film was dumuished due to the formation of a higher extent of cyclobutane in any directions that is far away of polarization direction of UV light.

Comparison of the optical anisotropy using the polyimide and polymethacrylate: In order to investigate the UV-induced optical ansotropy precisely. we observed the absorbance change durmg iradiation of a linearly polarized $\mathrm{He}$-Cd laser sinultaneously as a function of irradiation time. The absorption spectra were recorded by every $0.5 \mathrm{sec}$ under irradiation of the probe bean whose polarization is parallel and perpendicular to the polarization direction of the pump beam. In Figure 8. we could observe the traces of the parallel
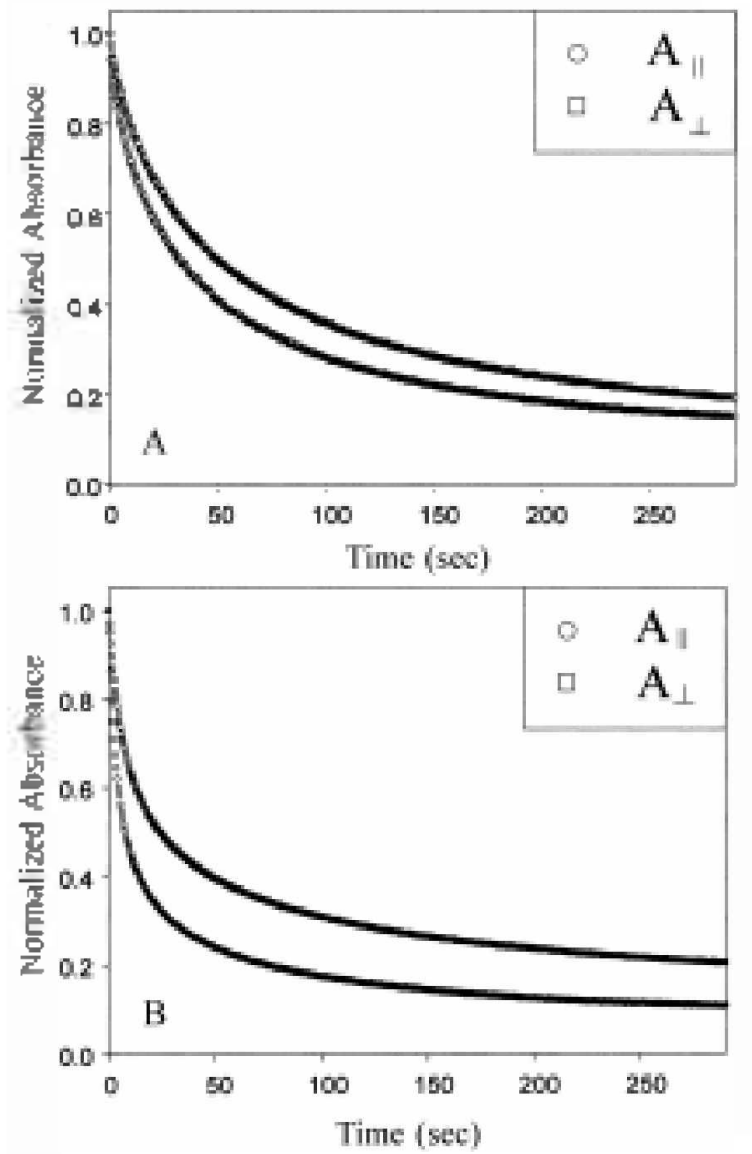

Figure 8. Change of polarized absorbance at $\rangle_{\text {milax }}$ as a function of UV esposure time. A: CSPI, B: PMAC. and perpendicular absorbance during UV irradiation. Normalized absorbance change in both parallel and perpendicular direction to the pump polarization direction was shown as a function of the exposure tme. The parallel absorbance is smaller than the perpendicular absorbance. At a glance. we could figure out that the difference of two absorbances in polymethacrylate is relatively larger.

We employed the dicluroism $\left(\triangle A=A_{1}-A_{\perp}\right)$ to compare those two anisotropic behaviors precisely. The dichuroism could be calculated by subtracting the perpendicular absorbance. $A_{\perp}$ from parallel absorbance, $A_{\|}$. which describes the optical anisotropy in the film. Exposure time dependence of the dichroism was shown in Figure 9. In the case of polymethacrylate, the dichroism decreased to -0.185 after $7.8 \mathrm{sec}$ exposure. (See Figure 9B) Then, the value gradually increased to -0.09 untl $300 \mathrm{sec}$ exposure. Therefore, the optical ausotropy from the unaxially aligned reactive molecules was reduced by contributing the photochemical reaction of the molecules away of the polarization direction of the pump bean

In the case of the polyminde in the mitial stage of irradiation, the dichroism decreased generally faster. After 20 sec exposure. the dichroism reached to -0.095 only that is far high. After long time exposure $(300 \mathrm{sec})$, the value of dicluroism increased to -0.043 . Two behaviors result in the difference of optical anisotropy under a LPL. The poly-
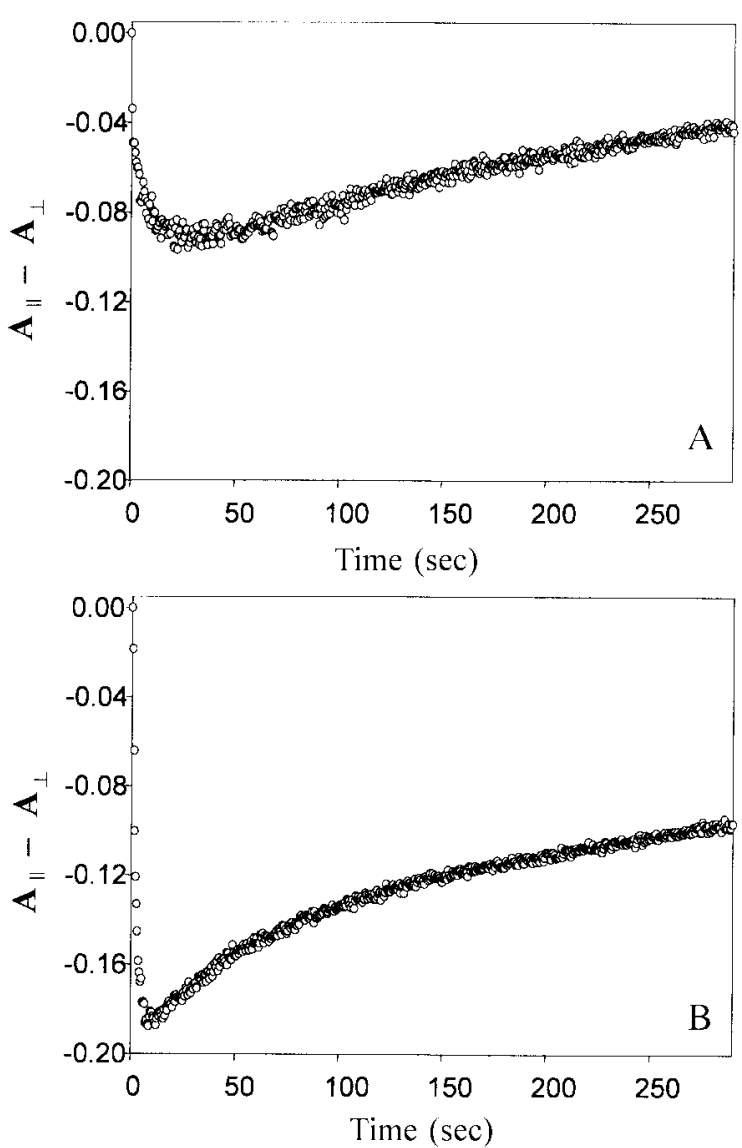

Figure 9. Exposure time dependence of dichroism of the two polymer fïlms. A: CSPI, B: PMAC 

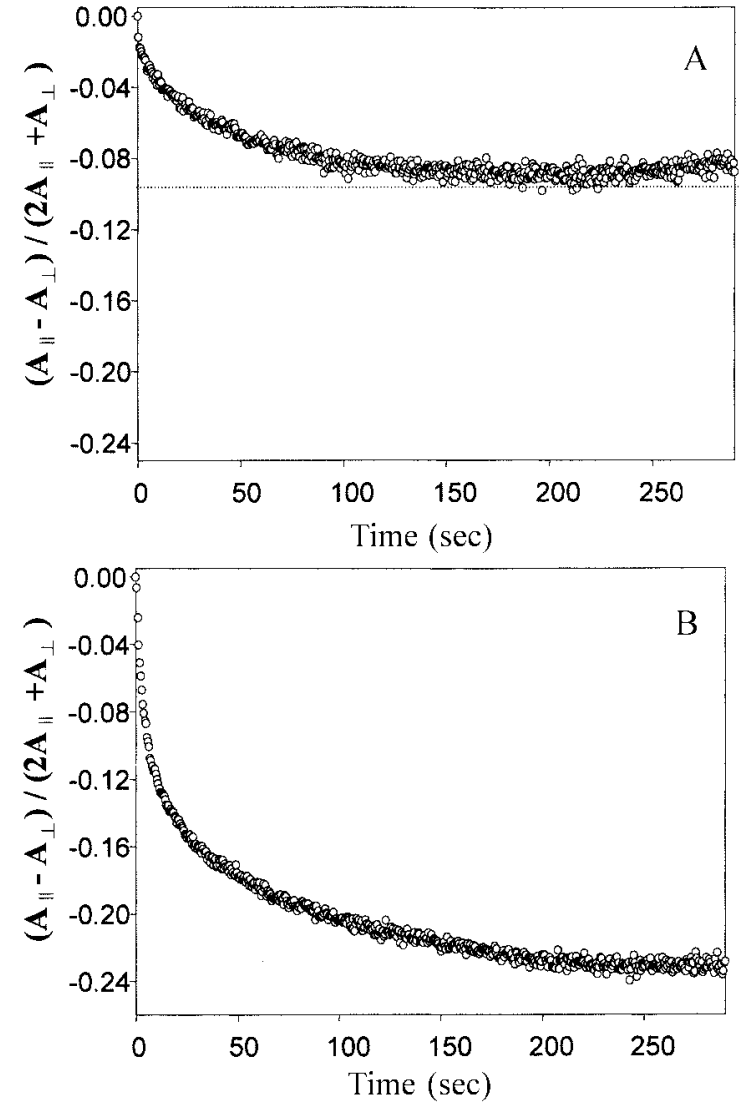

Figure 10. Exposure tine dependence of the order parameter of the two polymer films. A: CSPI, B: PMAC.

methacrylate with lower $T_{g}$ showed much higher optical anisotropy than the polyimide. As we mentioned previously. the density of the chalcone group in polymethacrylate is higher than that of polyimide. Since two chalcone units are tethered in the diamine unit of this polyimide, the distance between two groups is longer. Also. the backbone in this polyinide is much more rigid than that in the polymethacrylate.

We also could calculate the order parameters using the parallel and perpendicular absorption spectra. In Figure 10. exposure time dependence of the order parameter was described to observe the inducing optical anisotropy. The order parameter was calculated using the following equation (2).

$$
\text { Order Parameter (O.P.) }=\left[A_{\mid}-A_{\perp}\right] /\left[2 A_{\mid}+A_{\perp}\right]
$$

In the sample of polyinide. the order parameter decreased to -0.095 after $200 \mathrm{sec}$ exposure. Then, the value increased in a small positive rate during continuous irradiation due to reduction of the optical anisotropy. Contrary to that phenomenon. the value from the sample of polymethacrylate decreased quite fast at the initial stage of irradiation. And then the following reaction was retarded slightly.

Assuming that the order parameter and its changing behavior are mainly attributed to density of chalcone group and the geometrical hindrance around chalcone groups. this behavior in polymethacrylate is quite reasonably recognized. Although the irradiation continued longer subsequently, the order parameter of the sample of polymethacrylate decreased continuously to show higher anisotropy contpared to that in the sample of polyimide. This indicates that the azimuthal dimerization between chalcone groups is hardly formed in polymethacrylate film, since the rate of photodimerization is very large so that the conversion of cyclobutane may be very high. There is a very low concentration of the isolated chalcone group in polymethacrylate after $200 \mathrm{sec}$ irradiation of UV light.

The optical anisotropy from the linearly organized molecular structure in polymethacrylate and polyimide can be investigated and comparison was perfomed under our strategy. The properties of liquid crystal cell fabricated with the aligmment layer of two polymers will be described in our future report.

\section{Conclusion}

We synthesized photo-crosslinkable polyimide and polymethacrylate comprising chalcone group. Cyclobutane structures were formed under UV irradiation in two compounds between the side chains that were confinmed by spectroscopic analy sis.

We clarified anisotropic LP-UV photoreaction of polyimide and polymethacrylate compound. The dichroism of the photoreacted chalcone group was negative and very large when using as-coated polymethacrylate films. Owing to a large rate of photodimerization between the chalcone groups and the lower rigidity of the main chain, the value of optical anisotropy from the photodimerization was sustained much longer even under long-term UV exposure.

Acknowledgment. This work was financially supported by the Korea Research Foundation (KRF-2000-041-E00412).

\section{References}

1. Schadt. M.: Seiberle. H.: Schuster. A. Nature 1996.381. 212.

2. Lien. A.: Tohn1. R. A.: Angelopoulos. M.: Lee. K. W.: Takano. H.: Tajima. K.: Takenaka. A. Appl. Phos Lett 1995. 67(21). 20.

3. Murata. M.: Awaji. H.: Isurugi, M.; Uehita, M; Tawada. Y. $J p n . d$. Appl. Ply's. 1992, 31. L189.

4. Janning. J. Appl. Phus. Lett. 1992. $21,173$.

5. Congard. J. Aligment of Nematic Liquid Chstals and Their Mixzures: Gordon and Breach: New York. 1982.

6. Ichimura. K.: Hayashi. Y. Thin Solid Filhts 1993. 235. 101.

7. Park. B; Jung, Y; Choi. H.-H; Hwang. H.-K; Kim. Y.: Lee, S; Jang. S.-H.: Kakimoto, M.: Takezoe. H. Jph. J. Appl. Phus. 1998. 37. 5663 .

8. Ichimura. K. Chem. Review 2000. $100(5) .1847$.

9. O'Neill. M.: Kelly. S. M. J. Phos. D: Appl. Phos 2000. 33. R67.

10. Sekkat. Z.: Morichere. D.: Dumont. M.: Loucif-Saibi. R.: Delaire. J. J. Appl. Plps. 1992, 71, 1543 .

11. Ichimura. K.: Suzuki, T.: Kawanishi, Y.: Tamaki, T.: Aoki. K. 1 fakromol. Chem Rapid Conmun. 1989, 1,5.

12. Natansoht1. A.: Rochon. P.: Meng. X.: Barrett. C.: Buffeteau. T.: Bonenfant. S.: Pezolet. M. Hacromolecules 1998. 31. 1155.

13. Aoki. K.: Ichimura. K.: Tamaki. T.: Seki. T.: Kawanishi. Y. Kobunshi Ronbunsh 1990. 47.771.

14. Jain. S. C.: Kitzerow. H. S. Appl. Phus. Lett 1994. 64, 2946. 
15. Gibbon, W: Shannon, P. J: Sum, S.: Sweltin. B. I. Nahme 1991. 351.45 .

16. Ichimura. K. Liquid Crnstals 1996, 3.67.

17. Makita. Y: Natsui. T.: Kimura. S.: Kimura. M:: Matsuki. Y: Takeuchi. Y. J. Photopoh: Sci. Techlol. 1998.11. 187.

18. Nakata, S.: Matsuki. Y.: Natsui. T: Kimura. M.: Makita, Y. Proceedings of the Fifh Intemational Display Workshops 1998. 331.
19. Kawatsuki. N:- Takatani. K.: Yamamoto. T: Ono, H. Polym. d. 1998. 30.946

20. Akelah. A.: Selimn. A.: Salah El-Deen. N. Polym. International 1992. 28.307

21. Akelah. A.: Selim. A.; Salah El-Deen, N. Polym. Intemational 1993. 32, 423 .

22. Watanabe, S.: Harashima S.; Tsukada. N. J. Polym Sci. A Polym. Chent. Ed. 1986. 24. 1227. 